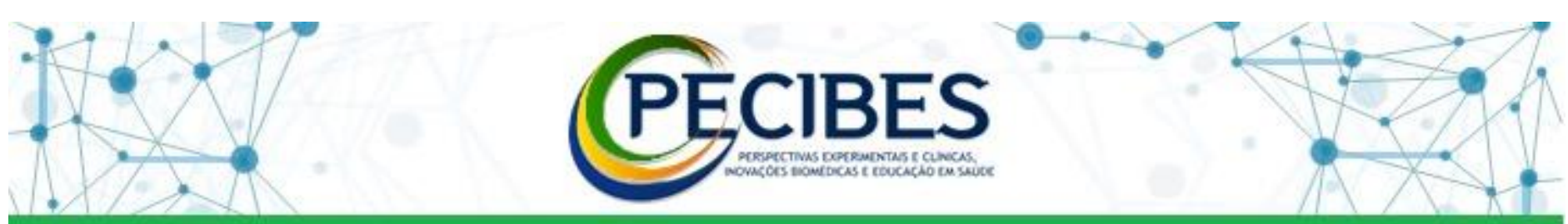

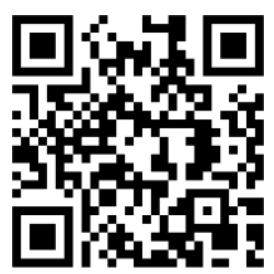

http://www.seer.ufms.br/in dex.php/pecibes/index

*Autorcorrespondente:Z adriane

Gasparetto,Universidade Federal do Mato Grosso do Sul UFMS. E-mail do autor:

zadriane_gasparetto@uf ms.br

Descritores:Ginástica. Crescimento.Desemp enho.

Key-words:

Gymnastic. Growth.

Performance.

Descriptores:

Gimnasia.

Crecimiento.

Rendimiento.

\section{Relação entre aspectos antropométricos e ocorrência de lesões esportivas em ginastas segundo o sexo}

Relationship between anthropometric aspects and the occurrence of sports injuries in gymnasts according to sex

Zadriane Gasparetto ${ }^{1}$, Nicole Iasmim Minante da Silva ${ }^{1}$, Higor Alexandre Alves de Oliveira ${ }^{1}$, Paula Felippe Martinez ${ }^{2}$, Sarita de Mendonça Bacciotti ${ }^{1}$; Silvio Assis de Oliveira-Junior ${ }^{2}$

1. Programa de Pós-Graduação em Ciências do Movimento, INISA/UFMS, Campo Grande MS,Brasil.

2. Programa de Pós Graduação em Ciências do Movimento/INISA/UFMS, Campo Grande - MS, Brasil.

Introdução. Classicamente, a prática competitiva de ginástica artística (GA) mostra-se associada com medidas reduzidas de estatura e massa corporal, assim como importante força muscular. No contexto biomecânico, essas características favorecem a execução de movimentos explosivos, típicos dessa modalidade, mas também favorece a instalação de lesões esportivas (LE). Objetivo. Descrever as características antropométricas e ocorrência de LE em praticantes de GA de acordo com o sexo. Métodos. A casuística foi constituída por 60 participantes, sendo 18 do sexo masculino e 42 do sexo feminino. A análise antropométrica integrou estimadores de massa corporal, estatura e composição corporal, os quais foram obtidos com uso de balança digital calibrada, estadiômetro e adipômetro científico, respectivamente. Para avaliar a adiposidade, foi utilizada equação e tabela de referência específicas para aplicação em crianças e adolescentes. Um inquérito de morbidade referida foi utilizado para registro de LE. Os dados antropométricos foram analisados com uso de teste t de Student sob nível de significância de 5\%. Outros resultados são apresentados de forma descritiva. A presente pesquisa foi aprovada pelo comitê de ética em pesquisa da UFMS, sob protocolo $\mathrm{n}^{\circ}$ 5.013.655, de 02 de outubro de 2021. Resultados. No aspecto antropométrico, o grupo feminino mostrou maior estatura $(1,44 \pm 0,19$ vs. $1,38 \pm 0,14 \mathrm{~m} ; \mathrm{p}=0,026)$ e massa corporal $(39,3 \pm 11,1$ vs. $32,8 \pm 7,9 \mathrm{~kg} ; \mathrm{p}=0,008)$ em comparação ao masculino. Em relação à adiposidade corporal, assim como para faixa etária, não foi verificada diferença devido ao sexo (p\&gt;0,05). Além disso, observou-se um total de 31 LE retrospectivas, com maior número de casos entre praticantes do sexo feminino $(n=24)$, em comparação ao masculino $(n=7)$. CONCLUSÃO. Jovens praticantes de GA do sexo feminino mostram maior estatura e massa corporal, em associação com maior ocorrência de LE em comparação a ginastas do sexo masculino. APOIO: UFMS, CAPES (Código: 001), CNPq. 